\title{
Preference for response-contingent vs. free reinforcement
}

\author{
K. GEOFFREY WHITE and PETER MITCHELL \\ Victoria University, Wellington, New Zealand
}

\begin{abstract}
Preference in rats for response-contingent reinforcement vs. free reinforcement was examined by manipulating the rate of free reinforcement relative to the rate of response-contingent reinforcement in concurrent variable-interval variable-time schedules. Preference was assessed in terms of the time allocated to the alternative reinforcement sources independently of the differential reinforcement distribution, and was shown to be equal for response-contingent and free reinforcement.
\end{abstract}

The phenomenon of responding in the presence of free food (or "contrafreeloading") has often been interpreted as a preference for work over freeloading (D'Amato, 1974). During the preference test of a typical contrafreeloading study, the animal is presented with a choice between responding for food and a cup filled with a large number of food pellets. Therefore, there are two factors which may determine the choice. First, the animal may engage in one of two possible behaviors, responding vs. taking free food. Second, there is a choice between a certain density of responsecontingent reinforcement and a high density of free food. In a previous study (Mitchell \& White, 1977), the rates of response-contingent and free reinforcement were equal. It was shown that rats' preference for response-contingent reinforcement was a function of the relative amount of prior exposure to the two reinforcement sources. In the present experiment, preference for response-contingent vs. free reinforcement was examined directly in the context of concurrent schedules which maintained choice behavior. By varying the rates of response-contingent and free reinforcement, preference for responding was assessed independently of the differential reinforcement distribution. The ratio of time allocated to the two reinforcement sources served as an index of preference (Baum, 1974; Baum \& Rachlin, 1969).

\section{METHOD}

\section{Subjects}

Nine male hooded rats approximately 180 days old were maintained at $80 \%( \pm 5 \%)$ of their free-feeding body weights. All rats were experimentally naive. Ad-lib water was available in

This report is based on results reported in an MA thesis submitted to the Victoria University of Wellington by the second author. Carol Logie and Melva Maguire assisted in the preparation of the manuscript. Reprints may be obtained from Dr. K. G. White, Department of Psychology, Victoria University of Wellington, Wellington, New Zealand. This paper is sponsored by Professor M.R. D'Amato, who takes full editorial responsibility. the home cages, and supplementary food was given following experimental sessions to maintain prescribed weights.

\section{Apparatus}

The experimental chamber described by Mitchell and White (1977) contained identical liquid dippers and stimulus lights at each end of the chamber and a response lever at the right end. The sheet aluminum floor was pivoted at the center so as to tilt when the animal changed sides. Thus, the amount of time allocated to each side of the chamber was measured.

\section{Procedure}

During 13 sessions of preliminary training the response was shaped, and rapid switching between the two alternatives was established by using multiple variable-interval (VI) variabletime (VT) schedules: first, multiple VI $10 \mathrm{sec}$ VT $10 \mathrm{sec}$, then multiple VI $30 \mathrm{sec}$ VT $30 \mathrm{sec}$, with components alternating every five reinforcements. As in the previous experiment (Mitchell \& White, 1977), all VI reinforcements were scheduled on the right and all VT reinforcements were scheduled on the left. All subjects received the same preliminary training. Subjects were matched and assigned to one of three groups (three subjects per group) on the basis of relative time spent on the right during the last 6 days of preliminary training.

Daily experimental sessions were then conducted in which the VI and VT schedules were concurrently available. Each session was of 45-min duration. The rate of reinforcement associated with the VT schedule was different for the three groups, while the average interreinforcement interval for the VI schedule was always $30 \mathrm{sec}$. Group 1 was trained with concurrent VI $30 \mathrm{sec}$ VT $30 \mathrm{sec}$, Group 2 with concurrent VI $30 \mathrm{sec}$ VT $90 \mathrm{sec}$, and Group 3 with concurrent VI $30 \mathrm{sec}$ VT $10 \mathrm{sec}$. A changeover from one side (or schedule) to the other started a changeover delay (COD) timer. A .5-sec COD operated for the first day and was gradually increased over a period of a week to a final value of $4.0 \mathrm{sec}$ (cf. Baum \& Rachlin, 1969). A changeover within a COD restarted the COD timer.

Both schedules ran continuously and independently until a reinforcement had been set up for a given schedule. A reinforcement scheduled for the left (VT) was delivered if the subject was standing on the left side of the chamber, and a reinforcement scheduled for the right (VI) was delivered if the subject was standing on the right of the chamber and responded. The tapes which programmed reinforcements did not stop during a COD unless a reinforcement was scheduled. No reinforcers were delivered during a COD. Both stimulus lights were on at all times except during a COD (cf. Baum \& Rachlin, 1969). The experiment terminated after 27 sessions under the final conditions. The number of leverpresses, time spent on the left and right, and the number of changeovers were recorded. 


\section{RESULTS AND DISCUSSION}

Table 1 presents time allocated to the VI and VT reinforcement sources, the numbers of reinforcements obtained from each source, the number of responses emitted, and the number of changeover responses averaged over the last five sessions for each subject. The response rate increased directly with increasing rate of VI reinforcement relative to the rate of VT reinforcement; the product-moment correlation between response rate and relative VI reinforcement rate was $\mathbf{9 2}$.

For the purpose of assessing preference, the logarithm of the ratio of the time allocated to the VT source to the time allocated to the VI source, and the logarithm of the ratio of VT reinforcements to VI reinforcements were calculated for each subject from the mean times and reinforcement frequencies averaged over the last five sessions (cf. Baum, 1974; Baum \& Rachlin, 1969). The $\log$ time ratios are shown as a function of the $\log$ reinforcement ratios in Figure 1. The equation of the best fitting straight line, calculated by the method of least squares, was $y=.98 x+.09$, and the percentage of variance it accounted for was $98 \%$. The dashed diagonal line in Figure 1 has a slope of 1 and passes through the point $(0,0)$.

The equation describing the data of Figure 1 has the general form

$$
\log \left(\mathrm{T}_{1} / \mathrm{T}_{2}\right)=\mathrm{a} \log \left(\mathrm{R}_{1} / \mathrm{R}_{2}\right)+\mathrm{c}
$$

or equivalently,

$$
\mathrm{T}_{1} / \mathrm{T}_{2}=\mathrm{k}\left(\mathrm{R}_{1} / \mathrm{R}_{2}\right)^{\mathrm{a}}
$$

where $T_{1}$ and $T_{2}$ are the times allocated to VT and VI reinforcement sources, and $R_{1}$ and $R_{2}$ are the VT and VI reinforcement frequencies. The constants $\mathrm{a}, \mathrm{c}$, and $\mathrm{k}$ (where $\mathrm{c}=\log \mathrm{k}$ ) are obtained empirically. The equation

Table 1

Time Allocated (Seconds) and Reinforcements Obtained in the VI and VT Reinforcement Sources, Responses Emitted, and Total Changeover Responses, Averaged Over the Last Five Sessions for Each Condition

\begin{tabular}{ccccccc}
\hline $\begin{array}{l}\text { Sub- } \\
\text { ject }\end{array}$ & \multicolumn{7}{c}{ Time in } & VT & Reinforcements & $\begin{array}{c}\text { Respon- } \\
\text { VI }\end{array}$ & VT & $\begin{array}{c}\text { Change- } \\
\text { ses }\end{array}$ & overs \\
\hline \multicolumn{7}{c}{ Group 1 (Concurrent VI 30 VT 30) } \\
44 & 729 & 1249 & 57.8 & 81 & 529.4 & 201.6 \\
43 & 662 & 1031 & 63.4 & 78 & 556.2 & 299.6 \\
49 & 665 & 1151 & 61.8 & 80 & 918.2 & 240.8 \\
\multicolumn{7}{c}{ Group 2 (Concurrent VI 30 VT 90) } \\
42 & 1040 & 702 & 72.6 & 27.8 & 738.6 & 286.2 \\
41 & 1460 & 559 & 76.6 & 26.8 & 1024.4 & 205.0 \\
53 & 1327 & 452 & 75.6 & 27.6 & 921.2 & 265.2 \\
45 & 68 & 2529 & 8.8 & 264.4 & 43.4 & 32.8 \\
50 & 184 & 2244 & 22.2 & 256.0 & 198.4 & 79.6 \\
46 & 255 & 2055 & 34.0 & 249.0 & 163.2 & 118.6 \\
\hline \multicolumn{7}{c}{ Group 3 (Concurrent VI 30 VT 10) } \\
\hline
\end{tabular}

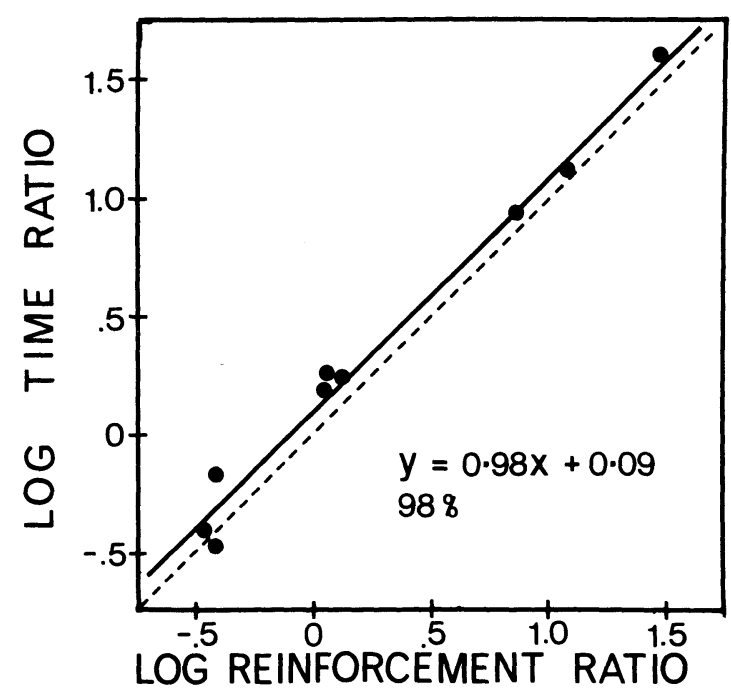

Figure 1. The logarithm of the ratio of time allocated to the VT reinforcement source to time allocated to the VI reinforcement source plotted as a function of the logarithm of the ratio of the frequency of obtained VT reinforcements to obtained VI reinforcements. The equation of the line of best fit (solid line) is given along with the percent of data variance it accounts for. The dashed line has a slope of 1 and passes through the origin $(0,0)$.

describes the way in which time allocated to the two reinforcement sources is dependent upon the reinforcement frequencies scheduled by the two sources. In particular, the parameter a describes the sensitivity of time allocation to the distribution of reinforcements between the two alternatives, and $\mathrm{c}$ describes the bias toward one or the other alternative (Baum, 1974; Davison \& Hunter, 1976). The bias parameter describes the deviation of the line of best fit from the origin, and provides an index of preference which is independent from the sensitivity of time allocation to relative reinforcement frequencies. For the data of Figure 1, the bias was very nearly zero $(c=.09)$. Therefore, it can be concluded that the subjects in the present experiment exhibited an equal preference for response-contingent and free reinforcement.

The result is entirely consistent with the data recently reported by Bauman, Shull, and Brownstein (1975) for the performance of pigeons in concurrent VI VT schedules. Although Bauman et al. did not report values for bias or sensitivity, their data suggest that the ratio of time allocated to VI and VT schedules perfectly matched the reinforcement ratios, as in the present experiment, and also that there was no bias for either VI or VT schedules. That is, preference for responsecontingent and free reinforcement was equal.

We conclude that when preference for free vs. responsecontingent reinforcement is assessed independently of the differential effects of different frequencies or rates of reinforcement, there is no bias for one or the other 
of the alternative reinforcement sources. The asymmetrical response requirement thus does not contribute to preference; responding for food is preferred equally to taking freely available food. Any preference that is observed for response-contingent reinforcement may, therefore, result from reinforcement rate differences (Morgan, 1974) or from differences in overall frequencies of reinforcement from the two sources during prior training (Mitchell \& White, 1977).

\section{REFERENCES}

BAUM, W. M. On two types of deviation from the matching law: Bias and undermatching. Journal of the Experimental Analysis of Behavior, 1974, 22, 231-242.

BAUM, W. M., \& RAChIIN, H. C. Choice as time allocation. Journal of the Experimental Analysis of Behavior, 1969, 12, 861-874.
Bauman, R. A., Shull, R. L., \& Brownstein, A. J. Time allocation on concurrent schedules with asymmetrical response requirements. Journal of the Experimental Analysis of Behavior, 1975, 24, 53-57.

D'Amato, M. R. Derived motives. Annual Review of Psychology, 1974, 25, 83-106.

Davison, M. C., \& Hunter, I. W. Performance on variableinterval schedules arranged singly and concurrently. Journal of the Experimental Analysis of Behavior, 1976, 25, 335-345.

Morgan, M. J. Do rats like to work for their food? Learning and Motivation, 1974, 5, 352-368.

Mrtchell, P., \& White, K. G. Responding in the presence of free food: Differential exposure to the reinforcement source. Bulletin of the Psychonomic Society, 1977, 10, 121-124.

(Received for publication November 2, 1976; revision received March 25, 1977.) 